\title{
Mapeamento do uso e cobertura da terra a partir da segmentação e classificação de imagens - fração solo, sombra e vegetação derivadas do modelo linear de mistura aplicado a dados do sensor TM/Landsat5, na região do reservatório de Tucuruí - PA.
}

\author{
Cíntia Honório VASCONCELOS ${ }^{1}$, Evlyn Márcia Leão de Moraes NOVO
}

\section{RESUMO}

Técnicas de sensoriamento remoto são fundamentais para o monitoramento das mudanças de uso da terra, principalmente em áreas extensas como a Amazônia. O mapeamento de uso da terra, geralmente é realizado por métodos de classificação manual ou digital pixel a pixel, os quais consomem muito tempo. Este estudo aborda a aplicação do modelo linear de mistura em uma imagem Landsat-TM segmentada para o mapeamento das classes de uso da terra na região do reservatório de Tucuruí-PA para os anos de 1996 e 2001.

PALAVRAS-CHAVE

mapeamento de uso da terra, sensoriamento remoto, segmentação de imagem.

\section{Mapping land use cover using segmentation and classification of fraction images, soil, shade and vegetation, derived from a linear mixing model applied to Landsat-5 TM data, Tucuruí reservoir region - Pará.}

\begin{abstract}
Remote sensing techniques are mandatory for monitoring land use changes in large areas such as the Amazon. Land use mapping is usually performed by both manual and digital pixel based classification methods which are cost and time-consuming. In this study an image segmentation approach is applied to unmix TM-Landsat images for mapping land use classes in Tucurui-PA reservoir region to 1996 and 2001.
\end{abstract}

KEY WORDS

mapping the land use, remote sensing, image segmentation.

\section{INTRODUÇÃO}

A Bacia Amazônica ocupa uma área de aproximadamente 6.600.000 $\mathrm{Km}^{2}$ pertencente ao Brasil, Colômbia, Equador, Peru, Bolívia e Venezuela. Apesar do desmatamento estar ocorrendo em todos os países que ocupa, no Brasil é mais intenso, sendo este o país que fornece dados mais precisos sobre alterações da cobertura da terra nessa região. As estimativas anuais de desmatamento são geradas pelo
Instituto de Pesquisas Espaciais, utilizando imagens de satélite que verificou no período de 10 anos, entre 1988 e 1998, que a área desmatada foi de $174.000 \mathrm{Km}^{2}$ com média de desmatamento na Amazônia brasileira de $15.000 \mathrm{Km}^{2}$ por ano, sendo que no período de 1994-1995 este número saltou para $29.000 \mathrm{Km}^{2}$. As principais áreas desmatadas coincidiram com a fronteira agrícola que avança em direção ao norte dos estados do Pará, Tocantins, Mato Grosso, Rondônia e Acre, formando o chamado "arco do

${ }^{1,2}$ Instituto Nacional de Pesquisas Espaciais (INPE), Cx. Postal 515, 12201-970; São José dos Campos -SP; E-Mail: cintia@ltid.inpe.br, evlyn@ltid.inpe.br 


\section{ACTA \\ AMAZONICA}

MAPEAMENTO DO USO E COBERTURA DA TERRA A PARTIR DA SEGMENTAÇÃO

E CLASSIFICAÇÃO DE IMAGENS - FRAÇÃO SOLO, SOMBRA E VEGETAÇÃO DERIVADAS... desmatamento". Os estados que mais desmataram foi Mato Grosso (por volta de $60.000 \mathrm{Km}^{2}$ ), seguido do Pará (57.000 $\mathrm{Km}^{2}$ ) e Rondônia $\left(23.000 \mathrm{Km}^{2}\right.$ ) (Wood, 2002).

Segundo Laurence et al. (2001) o desmatamento tem várias causas. Primeiro é o aumento de populações não indígenas desde 1960, de 2 a 20 milhões de pessoas que migraram para a região; segundo é o crescimento da indústria madeireira e mineradora, além do aumento da malha viária que permite maior acesso de fazendeiros e colonizadores; terceiro, avanço do desmatamento para o interior da bacia, antes se concentrava na parte leste e sudeste, mas agora as estradas, projetos madeireiros e de colonização, penetram no coração da bacia amazônica e finalmente, os incêndios provocados pela própria população no manejo das pastagens e de áreas para cultivo.

Para o estudo da dinâmica do desmatamento na Amazônia é imprescindível o uso das técnicas de sensoriamento remoto, principalmente devido a dimensão desta região associada à dificuldade de acesso. Uma das maiores dificuldades encontradas pelos usuários de dados de sensoriamento remoto reside, entretanto, na disponibilidade de método rápido e preciso para obter mapas de uso e cobertura da terra. A interpretação visual de imagens de satélites é um método muito utilizado para o mapeamento do uso e cobertura de imagens do sensor Thematic Mapper dos satélites da série Landsat. Apesar de ser uma técnica precisa ela se torna praticamente inviável, pela grande demanda de tempo, quando aplicada a áreas muito extensas. A alternativa aos métodos manuais é o uso de métodos de classificação digital. Até recentemente, os algoritmos disponíveis permitiam a classificação automática pixel a pixel. Os resultados desses métodos, entretanto, não geravam mapas de boa qualidade, demandando um grande tempo de edição posterior às classificações obtidas.

Os novos métodos de classificação automática (Nascimento,1997) baseados na segmentação de imagens e na classificação por regiões produzem resultados muito mais precisos.

A segmentação é o processo que permite que uma imagem seja subdividida em partes constituintes ou regiões, a partir de propriedades dos pixels, tais como nível de cinza e textura (Hussain, 1991). O algoritmo de segmentação por crescimento de regiões utilizado neste trabalho permite agrupar pixels ou sub-regiões em grandes regiões. A agregação é o método mais simples, o qual se inicia com um conjunto de pontos denominados "sementes" a partir dos quais crescem regiões através da incorporação dos pixels vizinhos que possuem propriedades similares como nível de cinza, textura e cor à cada uma delas (Gonzalez \& Wintz, 1987). Outra dificuldade encontrada para se obter uma classificação automática mais próxima à realidade, é a de que a radiância registrada por um satélite é a soma das radiâncias de vários materiais que estão dentro do campo de visada do sensor. Esta radiação detectada é a resultante da mistura de muitos materiais diferentes adicionada à contribuição da radiância atmosférica (Shimabukuro \&
Smith, 1991). É desejável, entretanto, que se possa conhecer a proporção dos diferentes materiais presentes em um pixel. Para isso, podem ser utilizados modelos que permitam a decomposição do pixel em seus componentes puros ou "endmembers".

O modelo linear de mistura espectral é uma ferramenta de processamento digital de imagens que permite separar as contribuições espectrais de cada objeto dentro de um pixel, a partir de um conjunto de componentes puros da imagem (Pereira et al., 1998).

A fórmula do modelo linear de mistura pode ser escrita como:

$$
\begin{aligned}
& r_{i}=\sum_{j=1}^{n}\left(a_{i j} x_{j}\right)+e_{i} \\
& r_{i}: \text { observação na banda } \mathrm{i} \\
& x_{j}: \text { proporção da componente } \mathrm{j} \\
& a_{i j}: \text { assinatura espectral para a componente } \mathrm{j} \text { na banda } \mathrm{i} \\
& e_{i}: \text { erro na banda } \mathrm{i} \\
& n: \mathrm{n}^{\circ} \text { de componentes } \\
& \text { Com a seguinte restrição: } \quad 0 \leq x_{j} \leq 1
\end{aligned}
$$

A partir da aplicação do algoritmo de mistura são geradas tantas imagens quantos forem as componentes puras identificadas pelo modelo. No caso específico do modelo desenvolvido por Shimabukuro \& Smith (1991), são consideradas componentes puras de um pixel de imagem TM - Landsat a vegetação, a sombra e o solo, sendo possível, portanto, decompor cada pixel de uma imagem nas proporções de sombra, vegetação e solo que o compõe. Essas imagens são conhecidas por imagens-fração.

O PRODES Digital (Projeto de Estimativa do Desflorestamento Bruto da Amazônia) desenvolvido pelo INPE, por exemplo, utilizou a imagem fração sombra para mapear áreas desflorestadas na Amazônia, pois áreas de floresta tropical são caracterizadas por apresentarem uma proporção considerável desta componente, enquanto que em áreas de pasto, regeneração de vegetação e solo exposto esta proporção é baixa (Shimabukuro et al., 1999).

O modelo linear de mistura também foi aplicado com sucesso para a discriminação de classes de floresta, cerrado, áreas preparadas para soja, culturas agrícolas e pastagem natural (Rodriguez Yi et. al., 1998), soja e milho (Moreira et al., 1998).

Com base nos resultados obtidos com o uso do modelo de mistura e classificação por regiões, optou-se por aplicar a mesma abordagem ao mapeamento do uso da terra na região do reservatório de Tucuruí - PA. Tendo em vista que o objetivo do mapeamento do uso e cobertura era a identificação tipos de uso do solo mais favoráveis à incidência de malária, foram definidas as seguintes classes: vegetação nativa não antropizada, vegetação em regeneração, corte seletivo, atividade agrossilvopastoril (áreas de pastagens, solo exposto e agricultura), área urbana e edificada, área alagada com 


\section{ACTA \\ AMAZONICA}

MAPEAMENTO DO USO E COBERTURA DA TERRA A PARTIR DA SEGMENTAÇÃO E CLASSIFICAÇÃO DE IMAGENS - FRAÇÃO SOLO, SOMBRA E VEGETAÇÃO DERIVADAS... vegetação, água, banco de areia e nuvem. Estas classes foram escolhidas porque apresentam diferentes potenciais de associação com a presença do vetor de transmissão da malária.

\section{Características gerais da área de estudo}

A área de estudo é delimitada pelas coordenadas $51^{\circ} 00$ e $48^{\circ} 30$ a oeste $5^{\circ} 30$ e $3^{\circ} 30$ a leste, engloba os municípios de Tucuruí, Jacundá e Novo Repartimento, além do reservatório de Tucuruí (Figura 1), formado pelo barramento do Rio Tocantins no Estado do Pará. É uma área de floresta tropical e o clima, segundo o método de classificação climática de Köpen é tropical úmido.

A partir dos anos 70 com a implantação do Plano de Desenvolvimento da Amazônia, esta área sofreu forte grau de antropização, principalmente com a construção da barragem de Tucuruí no Rio Tocantins, o que provocou a relocação de populações ribeirinhas e indígenas, um alto grau de urbanização e o agravamento dos problemas de saúde pública.

Esta região é considerada de difícil análise a partir de dados de sensoriamento remoto por apresentar um padrão de ocupação da terra de "espinha de peixe", onde um grande número de pequenas propriedades é distribuída ao longo de estradas (Alves et al., 1996). Este padrão faz com que haja um grande perímetro de transição entre diferentes classes de ocupação da terra. Além disso, nesse tipo de estrutura fundiária dominam as pequenas parcelas o que faz com que os dados atinjam condições limitantes sob o ponto de vista de resolução espacial.

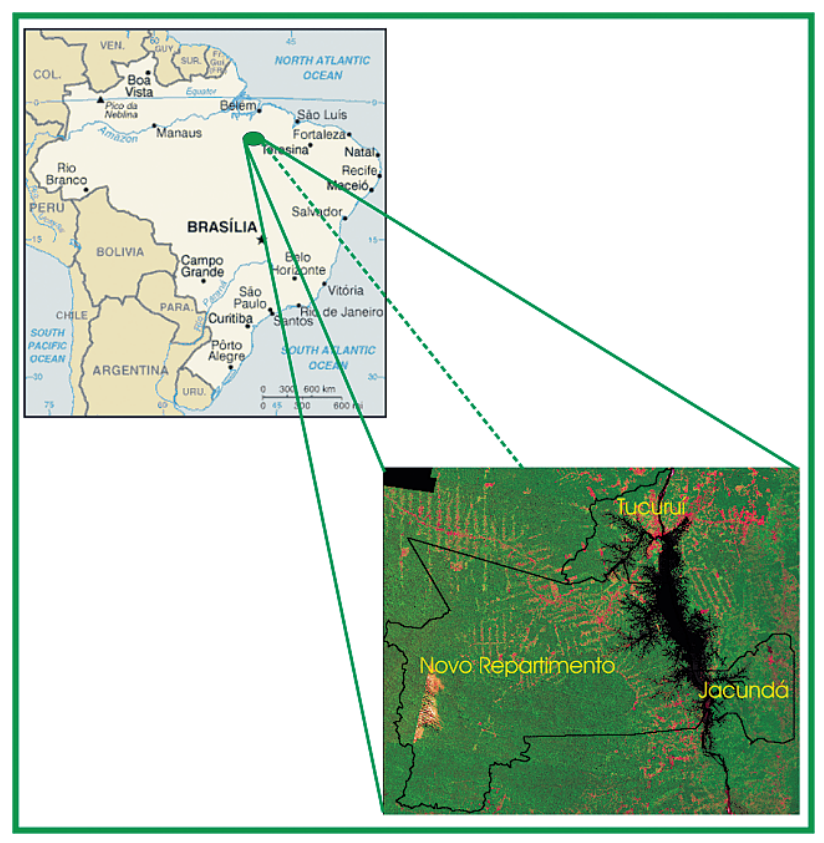

Figura 1 - Área de estudo.

\section{MATERIAIS E MÉTODOS}

No estudo foram utilizadas as seguintes imagens Landsat5-TM: 223/63, 64; 224/62, 63, 64; 225/63. Estas imagens foram georreferenciadas, usando como base as folhas topográficas do IBGE, que cobrem a área de estudo, na escala 1:100.000 em formato digital. Os dados foram processados no software SPRING 3.6 (Sistema de Processamento de Informações Georreferenciadas). Outra importante etapa do trabalho foi a aplicação do modelo linear de mistura espectral nas bandas originais 3, 4 e 5 TM-Landsat5 para gerar as três componentes referentes à vegetação, solo e sombra. $\mathrm{O}$ modelo linear de mistura utilizado para cada imagem foi obtido por meio de experimentos em áreas testes, representativas da imagem. A partir dos resultados desses experimentos o modelo foi aplicado para a cena inteira.

Após a obtenção das imagens fração, foi aplicado o algoritmo de segmentação de imagens (crescimento de regiões) para agrupar os "pixels" adjacentes e semelhantes gerando regiões homogêneas. Para cada imagem reamostrada para pixel de $60 \mathrm{~m}$, foram realizados testes com valores de limiares de similaridade e de área, sendo que a combinação com melhor resultado foi 8 e 16, limiares de similaridade e de área respectivamente. Esta combinação foi utilizada com bons resultados no Prodes Digital. O limiar de similaridade é o limiar mínimo, ou seja, "define a diferença mínima entre o valor de um pixel e o valor médio da região contígua a ele, para que este pixel possa ser agrupado a essa região. Se a diferença entre o valor do pixel e a média da região vizinha for maior que o valor de similaridade definida pelo usuário, o pixel não irá pertencer àquela região. O segundo limiar, de área, significa o menor valor de área (em pixel) para que uma região seja separada de outra" (Barbosa et al., 2000).

A seguir foram escolhidas as amostras de aquisição e teste representativas de cada uma das classes de interesse que foram utilizadas para treinar o algoritmo de classificação supervisionada por regióes (distância Battacharrya) disponível no SPRING. A chave de identificação das classes foram baseadas no Prodes Digital e no comportamento espectral dos alvos, principalmente em relação a resposta de solo e sombra do modelo linear de mistura. As classes seleciondas foram:

1. Vegetação Nativa não antropizada: foram inseridos nesta classe todos os tipos de formações florestais que não apresentassem nenhuma interferência antrópica.

2. Regeneração: nesta classe foram consideradas as áreas com vegetação em regeneração, florestas secundárias ou formações florestais que já tenham sofrido algum tipo de antropização, mas que ainda não regeneraram por completo.

3. Corte Seletivo: São áreas de floresta que vêm sofrendo a interferência antrópica através do corte somente das árvores que apresentam valor econômico.

4. Atividade Agrossilvopastoril: esta classe engloba áreas de solo exposto, que provavelmente seria utilizado para agricultura; áreas agrícolas e pecuária. 


\section{ACTA \\ AMAZONICA}

MAPEAMENTO DO USO E COBERTURA DA TERRA A PARTIR DA SEGMENTAÇÃO

E CLASSIFICAÇÃO DE IMAGENS - FRAÇÃO SOLO, SOMBRA E VEGETAÇÃO DERIVADAS...
5. Área Urbana e Edificada: nesta classe foram consideradas as manchas urbanas e obras de engenharia como a usina hidrelétrica.

6. Área Alagada com Vegetação: nesta classe considerouse as áreas alagadas com vegetação aquática.

7. Água: áreas ocupadas com água livre de vegetação, englobando os rios e lagos.

8. Banco de Areia: ilhas formadas por areia.

9. Nuvem: áreas cobertas por nuvem e por sombra de nuvem, sem informação espectral dos alvos encobertos.

O resultado da classificação supervisionada foi comparado às imagens obtidas pelo modelo de mistura $\mathrm{e}$ pelas respostas espectrais dos alvos nas bandas $3 \mathrm{R}, 4 \mathrm{G}$ e 5B do sensor TM-Landsat5. A partir disso, foi realizada a edição matricial dos polígonos mal classificados por classificação visual. Devido à grande dimensão e a dificuldade de acesso da região amazônica, é inviável verificar todas as áreas mapeadas, mas é possível fazer generalizações, amostrando áreas significativas de cada classe para obter mapas de verdade terrestre para comparar à classificação digital. Por isso, é imprescindível conhecer as principais classes que ocorrem na área de estudo, seus padróes e como se comportam espectralmente. O modelo linear de mistura foi desenvolvido e implementado no SPRING principalmente, para servir como uma importante ferramenta para melhorar a separabilidade das classes na região amazônica e suprir, em parte, a falta de informação de campo.

\section{RESULTADOS E DISCUSSÃO}

A segmentação das imagens fração do modelo linear de mistura foi ferramenta importante para a realização da classificação supervisionada das imagens TM-Landsat, para definir com maior segurança as classes de uso da terra. Os polígonos criados na segmentação foram úteis no momento de escolher as melhores amostras de cada classe para o treinamento do algoritmo classificador (Figura 2).

$\mathrm{O}$ uso da técnica de segmentação das imagens fração do modelo linear de mistura, permitiu uma boa separação entre regeneração e a classe agrossilvopastoril. Quando havia dúvidas em relação a uma área que poderia ser capoeira ou uma área de pasto, por exemplo, utilizou-se a imagem fração solo para definir a qual classe este polígono pertenceria.

Nas Figuras 3 (a e b), observa-se a comparação de uma área classificada como regeneração na imagem sintética de composição colorida 3R, 4G, e 5B e na imagem fração solo. Neste caso, a área indicada pela seta na imagem sintética poderia causar dúvidas entre classificar como agrossilvopastoril ou vegetação de regeneração. $\mathrm{Na}$ imagem fração solo, ficou claro que é uma área em regeneração com baixa resposta espectral de solo. Nas áreas de pastagens, a resposta do solo é alta devido à escassa cobertura vegetal por isso, são realçadas e aparecem na cor branca ou em tons de cinza claro.
A imagem fração solo também permitiu diferenciar entre corpos d'água e áreas de queimada, pois essas duas classes são confundidas na banda 4 do TM-Landsat 5 pois se apresentam com baixos valores de nível digital, responsáveis pela cor escura, em decorrência do elevado coeficiente de absorção da água e da matéria queimada na região do infravermelho, respectivamente. Na imagem solo a água é representada pela cor preta ou cinza escuro, enquanto que as áreas de queimada são representadas em tons de cinza claro porque apresentam alta resposta espectral do solo (Figuras 4a, 4b, 5a e 5b).

A fração sombra foi importante para separar áreas alteradas de áreas de floresta e distinguir áreas sujeitas a sombreamento, causado pelo relevo, das áreas de atividade agrossilvopastoril.

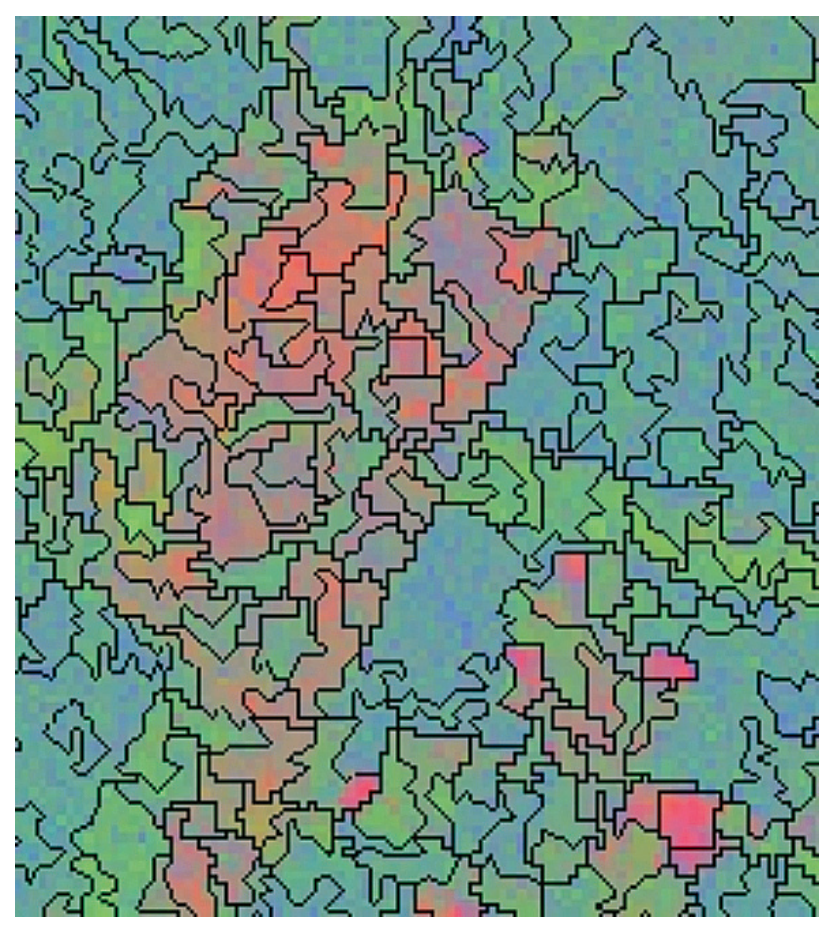

Figura 2 - Imagem fração solo, sombra e vegetação do modelo linear de mistura segmentada.

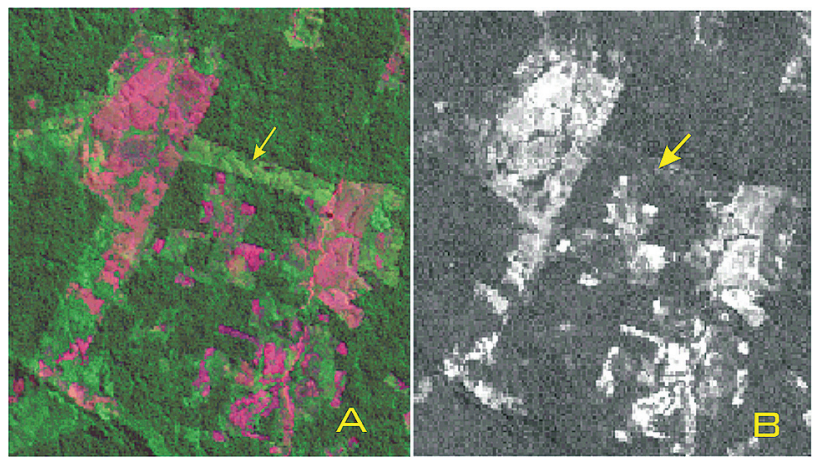

Figura 3 (a) e (b) - Comparação entre uma área classificada como rebrota na imagem sintética RGB (a) e na imagem fração solo (b). 


\section{ACTA AMAZONICA}

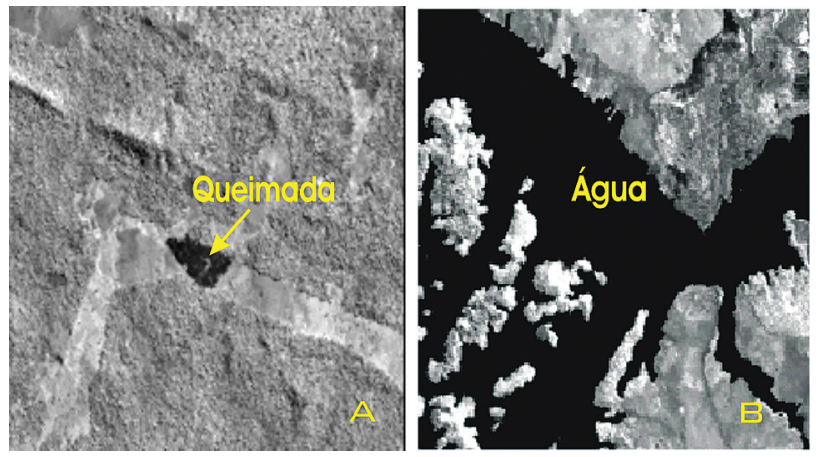

Figura 4 (a) e (b) - Comparação entre uma área de queimada (a) e de água (b) na banda 4 TM-Landsat.
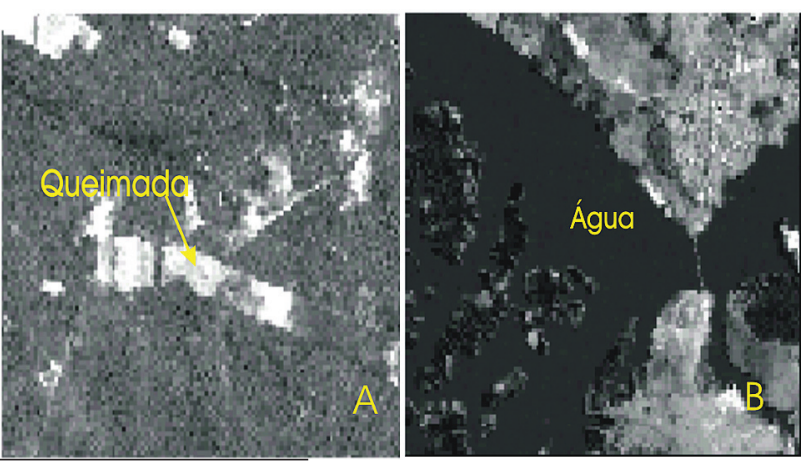

Figura 5 (a) e (b) - Comparação entre uma área de queimada (a) e de água (b) na imagem fração solo.

Após as etapas de processamento da imagem óptica TMLandsat, obteve-se a imagem classificada para uso da terra para o ano de 1996 (Figura 6) e 2001 (Figura 7).

Esses mapas permitiram gerar informações sobre a dinâmica, no tempo e no espaço, do uso e ocupação dos municípios que margeiam o reservatório de Tucuruí para um intervalo de cinco anos. A partir desses mapas pôde-se gerar os dados contidos nas Tabelas 1, 2 e 3 e gráficos das Figuras 8, 9 e 10.

As Tabelas 1, 2 e 3 apresentam os valores absolutos e relativos de área ocupada pelas classes de uso e ocupação da terra em 1996 e 2001 nos municípios de Jacundá, Tucuruí e Novo Repartimento.

Ao analisar as tabelas e figuras acima, pode-se observar que os municípios mais afetados pelo desmatamento foram os de Jacundá e Novo Repartimento. Em Jacundá a área ocupada por atividades agrossilvopastoris em 2001 foi quase duas vezes maior que a área ocupada em 1996, ou seja, passou de $504,2 \mathrm{Km}^{2}$ a $972 \mathrm{Km}^{2}$ (ver gráfico da Figura 10). No período de cinco anos este município perdeu o equivalente a $158,6 \mathrm{Km}^{2}$ de vegetação nativa ou 7,8\% da área total do município. Pode-se observar também que grande parte das áreas que estavam em processo de regeneração em 1996 (mais de 45\%), passou a ser ocupada por atividades agrossilvopastoris em 2001 (Figura 9).

O município de Novo Repartimento também perdeu grandes áreas de vegetação nativa para as atividades agrossilvopastoris. Em 1996 esta atividade ocupava 857,6 $\mathrm{Km}^{2}$ e passou a ocupar $1.685,22 \mathrm{Km}^{2} \mathrm{em} 2001$, um aumento de quase $100 \%$ (Figura 10). A área mais protegida do município de Novo Repartimento localiza-se na parte central, onde se encontra a reserva indígena dos Parakanãs. A vegetação nativa deste município no período estudado perdeu uma área de $839 \mathrm{Km}^{2}$, sendo o mesmo que 46 campos de futebol por dia.

O município de Tucuruí foi o que menos sofreu desflorestamento no período analisado, quando comparado aos demais. A área de vegetação nativa foi reduzida em 42,46 $\mathrm{Km}^{2}$, enquanto que a atividade agrossilvopastoril aumentou $67,76 \mathrm{Km}^{2}$ (Figuras 8 e 10). Este município é o que apresenta maior área atingida pelas águas do reservatório, aproximadamente $30 \%$.

Estes municípios desde o início da década de 80, quando a barragem de Tucuruí começou a ser construída, sofreu um forte incremento populacional. Segundo dados de população do IBGE, em 1970 Tucuruí e Jacundá tinham uma população de 9.930 e 2.225 , respectivamente e, na

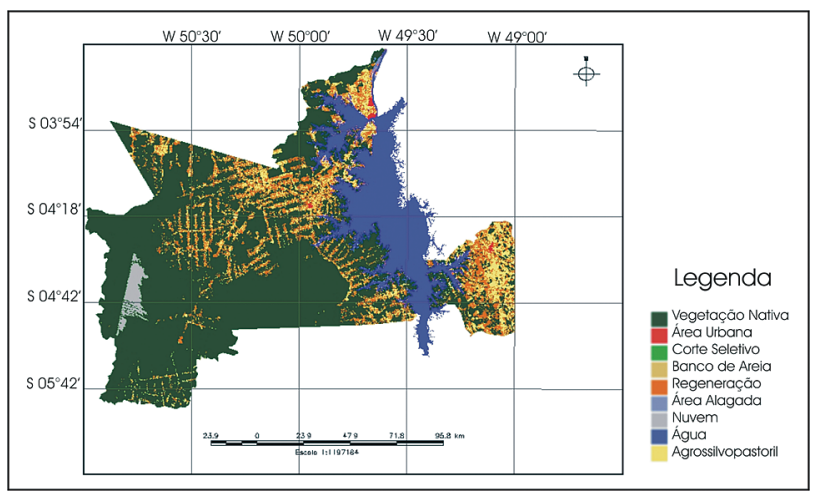

Figura 6 - Mapa temático de uso e ocupação da terra dos municípios de Tucuruí, Novo Repartimento e Jacundá derivado do processamento de imagens do sensor Thematic Mapper do satélite Landsat, referentes ao ano de 1996.

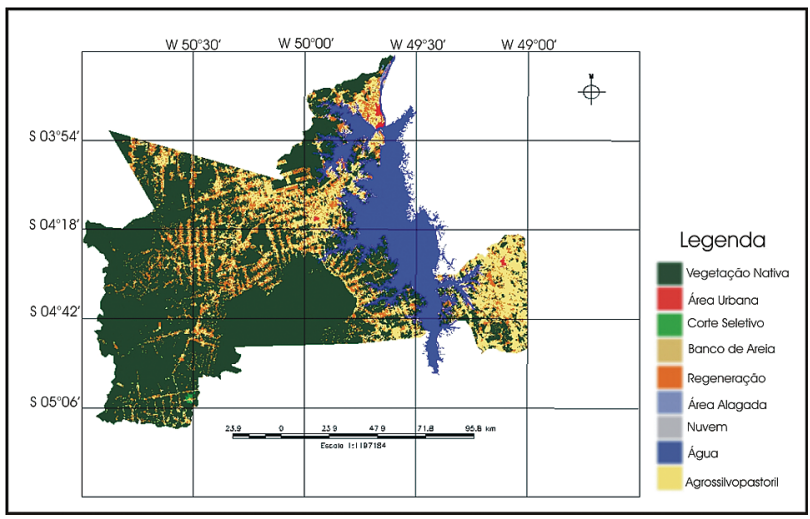

Figura 7 - Mapa temático de uso e ocupação da terra dos municípios de Tucuruí, Novo Repartimento e Jacundá derivado do processamento de imagens do sensor Thematic Mapper do satélite Landsat, referentes ao ano de 2001. 
Tabela 1 - Área em $\mathrm{Km}^{2}$ e porcentagem das classes de uso e ocupação da terra no município de Tucuruí em 1996 e 2001.

\begin{tabular}{ccccc}
\hline \hline Classes & $\begin{array}{c}\text { Área em } \\
\mathrm{Km}^{2} \text { para } \\
96\end{array}$ & $\begin{array}{c}\text { Área em } \\
\mathrm{Km}^{2} \text { para } \\
01\end{array}$ & $\% 96$ & $\% 01$ \\
\hline Veg_Nativa & $\mathbf{9 2 9 , 7 8}$ & $\mathbf{8 8 6 , 3 2}$ & $\mathbf{6 4 , 6 9}$ & $\mathbf{6 1 , 3 7}$ \\
\hline Regeneração & 263,52 & 226,58 & 18,33 & 15,69 \\
Água & 599,6 & 611,78 & 28,9 & 29,48 \\
Agros. & 234,64 & 302,4 & 16,32 & 20,94 \\
Área Alagada & 19,13 & 16,34 & 0,92 & 0,78 \\
Ar. Urbana & 19,64 & 23,34 & 1,36 & 1,6 \\
\hline \hline
\end{tabular}

Tabela 2 - Área em $\mathrm{Km}^{2}$ e porcentagem das classes de uso e ocupação da terra no município de Novo Repartimento em 1996 e 2001.

\begin{tabular}{ccccc}
\hline \hline Classes & $\begin{array}{c}\text { Área em } \\
\mathrm{Km}^{2} \text { para } \\
\mathbf{9 6}\end{array}$ & $\begin{array}{c}\text { Área em } \\
\mathrm{Km}^{2} \text { para } \\
\mathbf{0 1}\end{array}$ & $\begin{array}{c}\text { \% 96 } \\
\% 01\end{array}$ & \\
\hline Veg_Nativa & $\mathbf{1 1 . 2 7 9 , 1 0}$ & $\mathbf{1 0 . 4 3 9 , 8 2}$ & $\mathbf{8 2 , 1 3}$ & $\mathbf{7 4 , 6 3}$ \\
\hline Regeneração & $1.571,10$ & $1.846,11$ & 11,44 & 13,19 \\
Água & $1.403,24$ & $1.421,62$ & 9,1 & 9,22 \\
Agros. & 857,6 & $1.685,22$ & 6,24 & 12,04 \\
Área Alagada & 31,39 & 3,61 & 0,2 & 0,02 \\
Ar. Urbana & 3,84 & 4,01 & 0,02 & 0,03 \\
\hline \hline
\end{tabular}

Tabela 3 - Área em $\mathrm{Km}^{2}$ e porcentagem das classes de uso e ocupação da terra no município de Jacundá em 1996 e 2001.

\begin{tabular}{ccccc}
\hline \hline Classes & $\begin{array}{c}\text { Área em } \\
\mathrm{Km}^{2} \text { para } \\
96\end{array}$ & $\begin{array}{c}\text { Área em } \\
\mathrm{Km}^{2} \text { para } \\
\mathbf{0 1}\end{array}$ & $\% 96$ & $\% 01$ \\
\hline Veg_Nativa & $\mathbf{6 4 2 , 9 3}$ & $\mathbf{4 8 4 , 3 1}$ & $\mathbf{3 7}$ & $\mathbf{2 8}$ \\
\hline Regeneração & 580,32 & 264,17 & 33,47 & 15,27 \\
Água & 275,1 & 277,12 & 13,66 & 13,77 \\
Agros. & 504,19 & 971,89 & 29,08 & 56,2 \\
Área Alagada & 3,66 & 5,65 & 0,18 & 0,28 \\
Ar. Urbana & 7,8 & 8,71 & 0,44 & 0,5 \\
\hline \hline
\end{tabular}

década de 80, esses valores saltaram para 61.140 e 14.868 . A população desses municípios aumentou cerca de seis vezes em uma década. A partir desta época as áreas de floresta perderam espaço para assentamentos; abertura de estradas; projetos agropecuários; para a água do reservatório e para a ação dos madeireiros.

\section{CONCLUSÃO}

Os resultados da aplicação da técnica de segmentação das imagens fração- solo, sombra e vegetação do modelo linear de mistura mostraram-se satisfatórios para obter a separabilidade das classes e com isso, facilitou a seleção das amostras para realizar a classificação automática supervisionada nos anos de 96 e 2001.

As frações solo e sombra foram extremamente importantes para diferenciar as classes: vegetação nativa, regeneração e agrossilvopastoril.

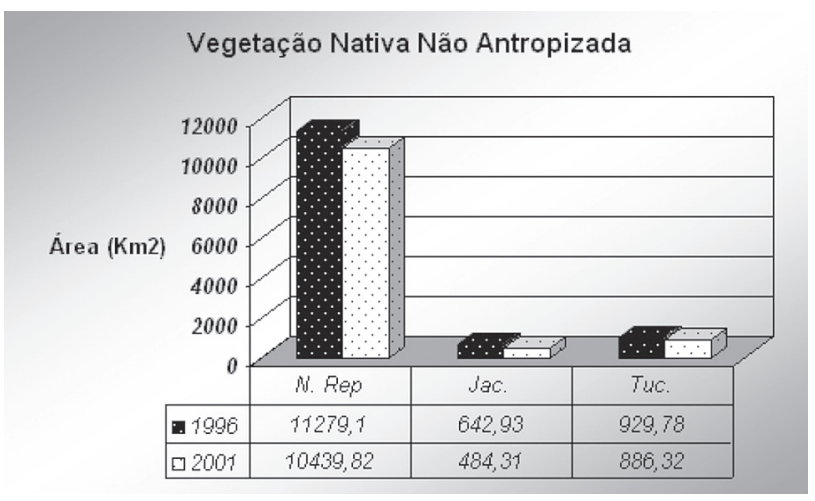

Figura 8 - Gráfico da alteração da área de vegetação nativa nos municípios para o período de 96 a 2001.

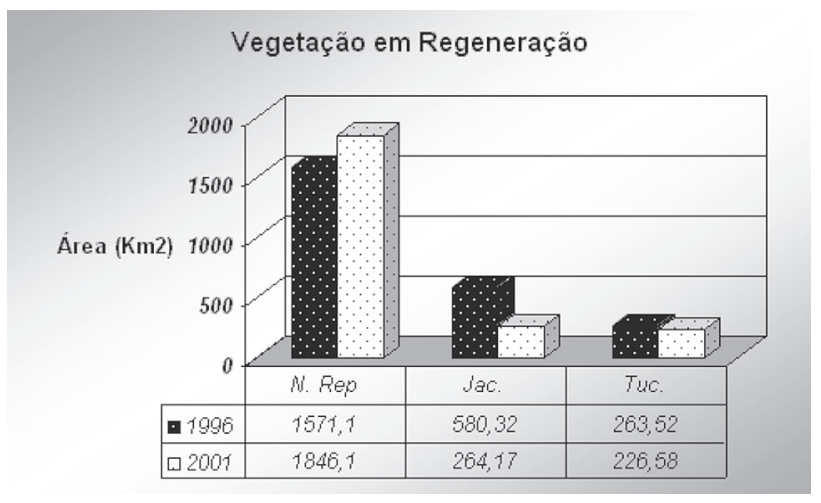

Figura 9 - Gráfico da alteração da área de vegetação em regeneração nos municípios para o período de 96 a 2001.

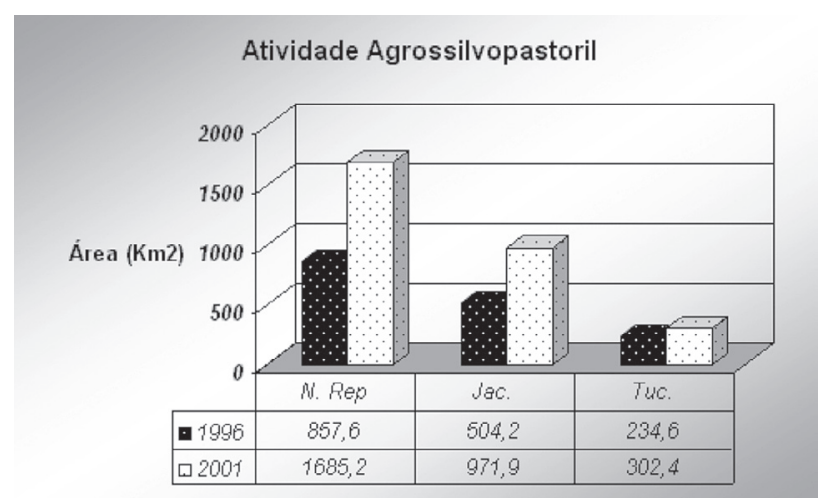

Figura 10 - Gráfico da alteração da área de atividade agrossilvopastoril nos municípios para o período de 96 a 2001. 


\section{ACTA AMAZONICA}

MAPEAMENTO DO USO E COBERTURA DA TERRA A PARTIR DA SEGMENTAÇÃO E CLASSIFICAÇÃO DE IMAGENS - FRAÇÃO SOLO, SOMBRA E VEGETAÇÃO DERIVADAS...
A classificação automática agilizou esta etapa do trabalho, sendo essa uma das maiores vantagens desta técnica, principalmente porque a área de estudo ocupa aproximadamente $19.500 \mathrm{Km}^{2}$.

\section{AGRADECIMENTOS}

Agradecemos à Fundação de Amparo à Pesquisa do Estado de São Paulo (FAPESP), processo n ${ }^{\circ}$ 01/07693-4 e ao Instituto Nacional de Pesquisas Espaciais (INPE) pelo suporte técnico.

\section{BIBLIOGRAFIA CITADA}

Alves, D.S.; Moreira, J.C.; Mello, E.M.K.; Soares, J.V.; Silva, O.F.; Almeida, S.A.S.; Ortiz, J.O.; Amaral, S. 1996. Mapeamento do uso da terra em Rondônia utilizando técnicas de segmentação e classificação de imagens TM. (CD ROM). In: Simpósio Brasileiro de Sensoriamento Remoto, Salvador. Anais. 392 $400 p p$.

Barbosa, C.; Hess, L.; Melack, J.; Novo, E. 2000. Mapping amazon wetlands through region growing segmentation and segmented-based classification JERS-1 data. (CD ROM). In: Simpósio Latino Americano de Sensoriamento Remoto, Puerto Iguazu, Argentina. Anais. 1065 - 1076pp.

Gonzalez, R.C.; Wintz, P.1987. Digital Image Processing. 2 ed. Addison-Wesley Publishing Company. 503p.

Hussain, Z. 1991. Digital Image Processing: practical applications of parallel processing techniques. Ellis Horwood. 406p.

Laurence, W.F.; Cochrane, M.A.; Bergen, S.; Fearnside, P.M.; Delamônica, P.; Barber, C.; D’Angelo, S.; Fernandes, T. 2001. The future of the Brazilian Amazon. Science Magazine, 291 (5503): 438.

Moreira, M.A.; Aulicino, L.C.M.; Shimabukuro, Y.E. et al. 1998. Modelo de mistura espectral para identificar e mapear áreas de soja e milho em quatro municípios do estado de Minas Gerais. In: Simpósio Brasileiro de Sensoriamento Remoto, Santos. CD ROM. Anais.
Nascimento, P.S.R. 1997. Avaliação de técnicas de segmentação e classificação em imagens Landsat-TM visando o mapeamento de unidades de paisagem na Amazônia. São José dos Campos. Dissertação (Mestrado) - Instituto Nacional de Pesquisas Espaciais, INPE. 120p.

Pereira, J.L.G.; Batista, G.T.; Thales, M.C.; Roberts, D.A. 1998. Proporção de componentes derivadas de imagens Landsat TM para caracterização da cobertura da terra na amazônia. (CD ROM). In: Simpósio Brasileiro de Sensoriamento Remoto, Santos.CD ROM Anais.

Shimabukuro, Y.E.; Smith, J.A. 1991. The least-squares mixing models to generate fraction images derived from remote sensing multispectral data. IEEE Transactions on Geoscience and Remote Sensing, 29(1):16-20.

Shimabukuro, Y.E.; Duarte, V.; Mello, E.M.K.; Moreira, J.C. 1999. RGB shade fraction images derived from multitemporal Landsat TM data for studying deforestation in the Brazilian Amazon. International Journal of Remote Sensing, 20(4):643-46.

Rodriguez Yi, J.L.; Aulicino, L.C.M.; Shimabukuro, Y.E.; Rudorff, B.F.T.; Duarte, V.; Moreira, M.A.; Martini, P.R.; Souza, I.M. 1998. Segmentação de imagens - fração derivadas do sensor TM Landsat para o mapeamento do uso do solo no município de Sapezal (MT). (CD ROM). In: Simpósio Brasileiro de Sensoriamento Remoto, Santos. Anais.

Wood, C.H. 2002. Land use and deforestation in the Amazon. University Press of Florida. Florida. 400p
RECEBIDO EM 20/09/2002
ACEITO EM 14/05/2004 